\title{
Aplicação de metodologia baseada em critérios empíricos para priorização de inspeções diagnósticas em reservatórios de água, em Sergipe.
}

\author{
Francisco Luiz Campos Lopes ${ }^{1 *}$, Monalisa Matisse Barreto Oliveira ${ }^{2}$, Natalia Shirley Carvalho \\ Matos $^{3,}$ Emerson Meireles de Carvalho ${ }^{4}$ \\ *Autor de Contato: francisco.campos.lopes@gmail.com
${ }^{1}$ Departamento de Engenharia Civil, Instituto Federal de Ciência e Tecnologia de Sergipe
${ }^{2}$ MM Engenharia Diagnóstica e Consultoria
${ }^{3}$ Departamento de Engenharia Mecânica, Universidade Federal de Sergipe
${ }^{4}$ Departamento de Engenharia Civil, Universidade Federal de Sergipe

\begin{abstract}
RESUMO
A realização de inspeções e manutenções periódicas para garantia da integridade e do desempenho da estrutura é indispensável. Visando a orientação para elaboração de um plano de manutenção e recuperação de reservatórios em Sergipe, elaborou-se uma metodologia de análise qualiquantitativa, objetivando uma priorização das estruturas para posterior perícia diagnóstica. Inspecionou-se a nível 1, 49 reservatórios, sendo estes de concreto armado com mais de 20 anos, avaliando as anomalias e manifestações patológicas com o uso de uma matriz GUT, associada a parâmetros de impacto econômico e risco à vida humana. A metodologia obteve um referencial técnico para auxílio de uma tomada de decisão para a realização de uma inspeção a nível $2 \mathrm{e}$ desenvolvimento do projeto de recuperação e reforço.
\end{abstract}

Palavras-chave: Inspeção predial, Reservatórios de água, Matriz GUT.

\section{Aplicación de la metodología basada en criterios empíricos para priorizar las inspecciones diagnósticas en los embalses de Sergipe.}


Francisco Luiz Campos Lopes ${ }^{1 *}$, Monalisa Matisse Barreto Oliveira ${ }^{2}$, Natalia Shirley Carvalho Matos $^{3,}$ Emerson Meireles de Carvalho ${ }^{4}$

*Autor de Contacto: francisco.campos.lopes@gmail.com

${ }^{1}$ Departamento de Ingeniería Civil, Instituto Federal de Ciencia y Tecnología de Sergipe

${ }^{2}$ MM Engenharia Diagnóstica e Consultoria

${ }^{3}$ Departamento de Ingeniería Mecánica, Universidad Federal de Sergipe

${ }^{4}$ Departamento de Ingeniería Civil, Universidad Federal de Sergipe

\section{RESUMEN}

La realización de inspecciones y mantenimientos periódicos para garantizar la integridad y desempeño de la estructura es fundamental. Con el objetivo de orientar el desarrollo de un plan de mantenimiento y recuperación de los embalses en Sergipe, se desarrolló una metodología de análisis cualitativo-cuantitativo, con el objetivo de priorizar las estructuras para una mayor experiencia de diagnóstico. En el nivel 1 se inspeccionaron 49 embalses, siendo estos de hormigón armado con más de 20 años, evaluando las anomalías y manifestaciones patológicas mediante una matriz GUT, asociadas a parámetros de impacto económico y riesgo a la vida humana. La metodología obtuvo una referencia técnica para ayudar a la toma de decisiones para realizar una inspección de nivel 2 y desarrollo del proyecto de recuperación y refuerzo.

Palabras clave: Inspección de edificios, reservorios de agua, matriz GUT.

\section{Methodology application based on empirical criteria for prioritizing diagnostic inspections in water reservoirs in Sergipe.}


Francisco Luiz Campos Lopes ${ }^{1 *}$, Monalisa Matisse Barreto Oliveira ${ }^{2}$, Natalia Shirley Carvalho Matos $^{3,}$ Emerson Meireles de Carvalho ${ }^{4}$

* Contact Author: francisco.campos.lopes@gmail.com

${ }^{1}$ Department of Civil Engineering, Federal Institute of Science and Technology of Sergipe

${ }^{2}$ MM Engenharia Diagnóstica e Consultoria

${ }^{3}$ Department of Mechanical Engineering, Federal University of Sergipe

${ }^{4}$ Department of Civil Engineering, Federal University of Sergipe

\begin{abstract}
The performance of periodic inspections and maintenance to guarantee the integrity and performance of the structure is essential. Aiming to guide the development of a maintenance and recovery plan for reservoirs in Sergipe, a qualitative-quantitative analysis methodology was developed, aiming at prioritizing structures for further diagnostic expertise. At level 1, 49 reservoirs were inspected, these being reinforced concrete with more than 20 years, evaluating anomalies and pathological manifestations using a GUT matrix, associated with parameters of economic impact and risk to human life. The methodology obtained a technical reference to aid decision making to carry out a level 2 inspection and development of the recovery and reinforcement project.
\end{abstract}

Keywords: Building Inspection, Water Reservoirs, GUT Matrix.

\title{
1. INTRODUÇÃO
}


O mercado da construção civil brasileiro tem experimentado os impactos econômicos do envelhecimento de seus empreendimentos e percebido a real importância da inspeção predial, seja a construção antiga ou nova.

O processo da vistoria durante a inspeção é imprescindível para uma boa classificação das não conformidades, anomalias e manifestações patológicas instaladas e visíveis encontradas na estrutura, destacando sua criticidade, risco a vidas humanas, impacto econômico, dentre outros fatores.

A Inspeção Predial é dita pelo IBAPE (2012) como sendo uma ferramenta que propicia a avaliação sistêmica de uma edificação. O IBAPE (2012) e a NBR 16747 (2020) explicitam a necessidade da periodicidade nas inspeções prediais para a mitigação de riscos técnicos e econômicos.

Conforme o IBAPE (2007), a inspeção predial é dividida em três níveis, proporcionais à complexidade da vistoria realizada. O nível 1 visa apenas a identificação das anomalias e falhas aparentes, enquanto a inspeção a nível 2 faz o uso de aparelhos, bem como documentos técnicos específicos, para identificar anomalias e falhas existentes. O nível 3 por sua vez, já é considerado como uma auditoria técnica, abordando uma construção de maior complexidade e elaborando planos de gerenciamento e manutenção. No presente trabalho somente se usou de uma inspeção a nível 1 com objetivo de subsidiar futuras inspeções a nível 2 com uso de ensaios não destrutivos.

A matriz GUT (gravidade, urgência e tendência) é a representação de problemas, ou riscos potenciais, através de quantificações que buscam estabelecer prioridade para abordá-los. A matriz é considerada por Lucinda (2010) como sendo uma ferramenta de priorização baseada na análise de parâmetros de representatividade dos problemas de um sistema. Uma vez que associada à inspeção de nível 1, a matriz proporciona uma avaliação sistemática quali-quantitativa dos elementos estruturais e sistemas construtivos.

Somente no estado de Sergipe degradação de estruturas associada à falta de manutenção foi responsável por diversos acidentes e em alguns casos com vítimas fatais e grande prejuízo à população, como é o caso da ruína da caixa d'água em Dores (2017), a queda da peça metálica do shopping Jardins (2016) e o desabamento da ponte José Américo de Almeida em Pedra Branca (2015).

Dentro desta perspectiva, o artigo em tela apresenta uma proposta metodológica quali-quantitativa desenvolvida para a vistoria de 49 reservatórios de água de abastecimento de água dos tipos: elevado (REL) e apoiado (RAP), sendo estes de concreto armado com idades de construção de 20 a 40 anos.

\section{DESENVOLVIMENTO}

Inicialmente foi desenvolvido um checklist para a vistoria dos reservatórios, sendo este uma coleta de dados padrão para caracterização da estrutura de reservação, suas regiões limítrofes e as manifestações patológicas e/ou anomalias que neles houvessem.

De modo a melhor investigar os riscos e classes de desempenho, os elementos estruturais dos reservatórios foram analisados individualmente conforme explicitado na Figura 1. As não conformidades e manifestações patológicas presentes nos reservatórios que afetavam as suas funcionalidades e/ou durabilidades foram identificadas e classificadas. Ademais as áreas afetadas pelas anomalias e manifestações patológicas foram aferidas de modo qualitativo. 


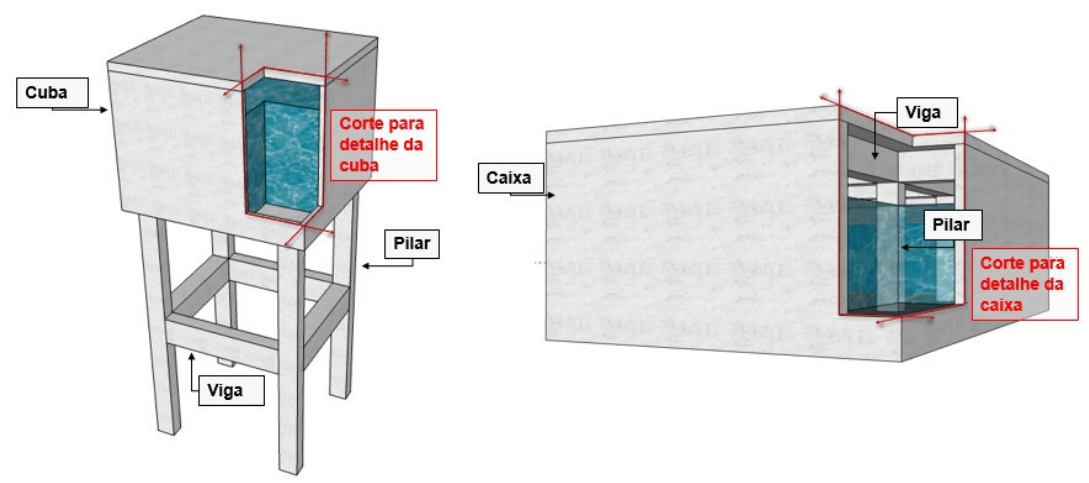

Figura 1. Identificação dos elementos estruturais.

Fonte: Autor (2021)

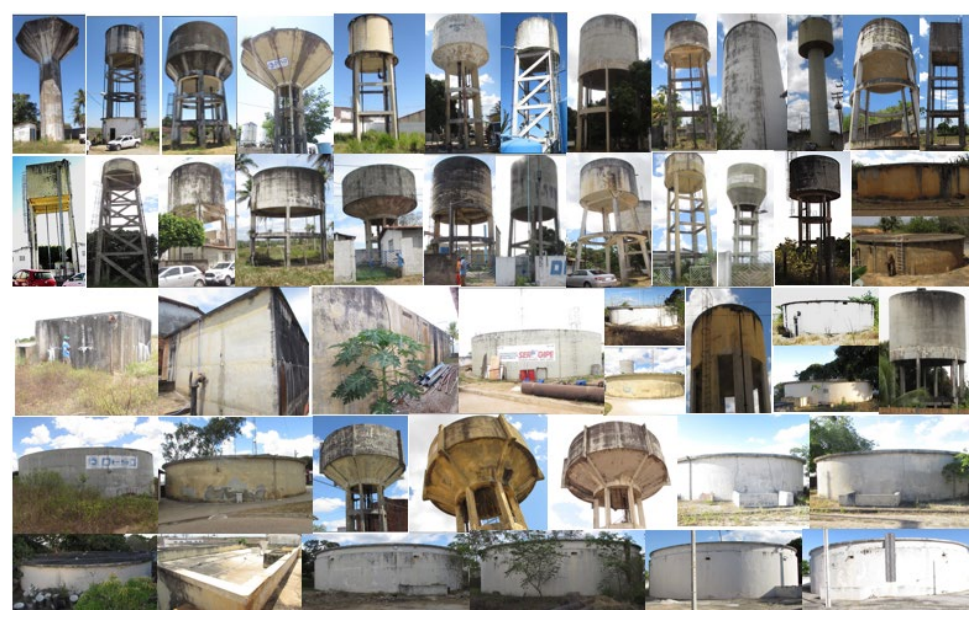

Figura 2. Representação dos 49 reservatórios vistoriados. Fonte: Autor (2021)

As anomalias e manifestações patológicas encontradas nos elementos estruturais dos reservatórios foram classificadas diante de sua gravidade, urgência e tendência utilizando a matriz GUT (Tabela 1) proposta por Gomide, Pujadas e Fagundes Neto (2009). A Tabela 2 por sua vez expõe a nota GUT resultante das anomalias e/ou manifestações patológicas observadas.

Tabela 1. Matriz GUT

\begin{tabular}{|c|c|c|}
\hline Grau & Gravidade & Peso \\
\hline Total & Perda de vidas humanas, do meio ambiente ou do próprio edifício & 10 \\
\hline Alta & Ferimentos em pessoas, danos ao meio ambiente ou do edifício & 8 \\
\hline Média & Desconfortos, deterioração do meio ambiente ou do edifício & 6 \\
\hline Baixa & Pequenos incômodos ou pequenos prejuízos financeiros & 3 \\
\hline Nenhuma & - & 1 \\
\hline Grau & Urgência & Peso \\
\hline Total & Evento em ocorrência & 10 \\
\hline Alta & Evento prestes a ocorrer & 8 \\
\hline Média & Evento prognosticado para breve & 6 \\
\hline Baixa & Evento prognosticado para adiante & 3 \\
\hline
\end{tabular}




\begin{tabular}{|c|c|c|}
\hline Nenhuma & Evento imprevisto & 1 \\
\hline Grau & Tendência & Peso \\
\hline Total & Evolução imediata & 10 \\
\hline Alta & Evolução em curto prazo & 8 \\
\hline Média & Evolução em médio prazo & 6 \\
\hline Baixa & Evolução em longo prazo & 3 \\
\hline Nenhuma & Não vai evoluir & 1 \\
\hline
\end{tabular}

Fonte: Gomide, Pujadas e Fagundes Neto (2009).

Tabela 2. Matriz GUT das anomalias e/ou manifestações patológicas observadas

\begin{tabular}{|c|c|c|c|c|}
\hline Descrição da irregularidade & G & $\mathbf{U}$ & $\mathbf{T}$ & $\mathbf{G} \times \mathbf{U} \times \mathbf{T}$ \\
\hline Fissuras e trincas & 6 & 3 & 3 & 54 \\
\hline Infiltração & 6 & 10 & 6 & 360 \\
\hline Lixiviação do concreto & 3 & 3 & 3 & 27 \\
\hline Perda de seção do cobrimento de concreto & 8 & 10 & 6 & 480 \\
\hline Corrosão eletroquímica & 6 & 10 & 6 & 360 \\
\hline Deterioração do concreto & 6 & 3 & 1 & 18 \\
\hline
\end{tabular}

Fonte: Autor (2021).

Para a obtenção de uma análise quali-quantitativa dos elementos estruturais dos reservatórios foram aferidas durante a realização da vistoria, as áreas afetadas pelas anomalias e/ou manifestações patológicas instaladas nos mesmos, utilizando como referência de classificação a Tabela 3.

Tabela 3. Porcentagens qualitativas de área afetada.

\begin{tabular}{|c|c|}
\hline Área afetada (af) & Degradação do elemento estrutural \\
\hline af $=0 \%$ & $\begin{array}{c}\text { Não apresenta manifestação da anomalia e/ou manifestação } \\
\text { patológica. }\end{array}$ \\
\hline $0 \%<$ af $<25 \%$ & $\begin{array}{l}\text { Pouca influência de anomalia e/ou manifestação patológica, } \\
\text { iniciação da mesma; Sem riscos à segurança. }\end{array}$ \\
\hline $25 \%<$ af $<50 \%$ & $\begin{array}{c}\text { Presença significante da anomalia e/ou manifestação patológica, } \\
\text { propagação da mesma; Risco baixo à segurança. }\end{array}$ \\
\hline $50 \%<$ af $<75 \%$ & $\begin{array}{l}\text { Estado crítico, anomalia e/ou manifestação patológica instalada de } \\
\text { forma generalizada; Risco médio à segurança. }\end{array}$ \\
\hline $75 \%<$ af $\leq 100 \%$ & $\begin{array}{l}\text { Elemento inutilizado pela anomalia e/ou manifestação patológica; } \\
\text { Risco alto à segurança. }\end{array}$ \\
\hline
\end{tabular}

Fonte: Autor (2021).

Para encontrar a prioridade de cada um dos reservatórios foi elaborado um modelo de cálculo para obtenção de uma pontuação. O modelo considera o somatório das áreas afetadas por anomalias e/ou manifestações patológicas multiplicada por sua respectiva pontuação da matriz GUT, sendo passível de majoração caso necessário como de acordo com a Tabela 4. 
Tabela 4. Majorações consideradas.

\begin{tabular}{|c|c|}
\hline Situação & Majoração (M) \\
\hline Reservatório elevado com desaprumo & $50 \%$ \\
\hline Risco humano alto - Risco de acidentes com perda de vidas humanas & $50 \%$ \\
\hline Risco humano baixo - Risco de acidentes com danos materiais à \\
população & $25 \%$ \\
\hline $\begin{array}{c}\text { Alta interferência na rede de distribuição de água - Reservatórios de } \\
\text { grande volume (acima de } 200 \mathrm{~m}^{3} \text { ) ou com muitos dependentes de } \\
\text { abastecimento }\end{array}$ & $50 \%$ \\
\hline $\begin{array}{c}\text { Média interferência na rede de distribuição de água - Reservatórios de } \\
\text { grande capacidade (acima de 200m }{ }^{3} \text { ) que abastecem a sede }\end{array}$ & $25 \%$ \\
\hline Presença de vazamentos na cuba & $25 \%$ \\
\hline $\begin{array}{c}\text { Majoração da parcela das anomalias nos pilares na pontuação do } \\
\text { reservatório }\end{array}$ & $30 \%$ \\
\hline
\end{tabular}

Fonte: Autor (2021).

O cálculo da pontuação do reservatório é apresentado na equação 1 e 2:

$M a j=\prod(1+M)$

Pontuação $=M a j *\left(\sum(a f * G U T)\right)$

Onde Maj = majoração total adotada; $\mathrm{M}$ = majoração adotada de acordo com a situação do reservatório; af = área afetada pela respectiva anomalia e/ou manifestação patológica; GUT = pontuação GUT da respectiva anomalia e/ou manifestação patológica; Pontuação = pontuação usada para a priorização dos elementos.

\section{RESULTADOS}

\subsection{Da análise do risco humano e impacto dos reservatórios}

A respeito do risco humano considerou-se a presença de habitações adjacentes aos reservatórios e o grau de deterioração destes. Os REL's possuem um risco humano superior aos apoiados, dado que, na hipótese de ruína destes, o elevado tombaria sua estrutura para o lado mais degradado, podendo atingir uma habitação e gerar vítimas fatais. No caso do RAP a sua ruína representaria um risco médio com danos materiais e financeiros à região, uma vez sua água armazenada seria liberada de modo súbito.

Outro parâmetro de suma importância para a tomada de decisão em caso de recuperação é o impacto do reservatório para a rede de abastecimento. Tendo em vista que esse implica na paralisação das atividades.

Dos 49 reservatórios vistoriados 29 eram elevados e 20 eram apoiados. Enquanto os REL's encontram-se no meio urbano, a maior parte dos RAP's situam-se em regiões mais isoladas, sendo estes de transição entre as regiões de abastecimento. Como pode ser observado na Figura 4, os RAP's apresentam um maior impacto no abastecimento hídrico, por serem em sua maior parte de transição e possuírem uma maior capacidade de armazenamento de água. 

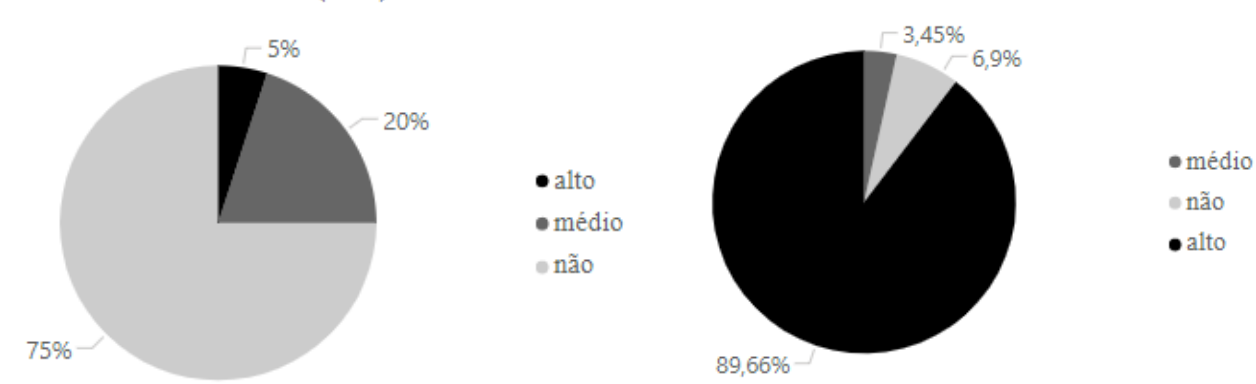

Impacto à rede de distribuição (RAP)
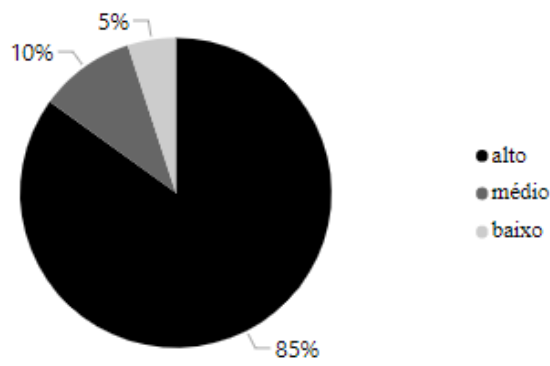

Impacto à rede de distribuição (RAP)

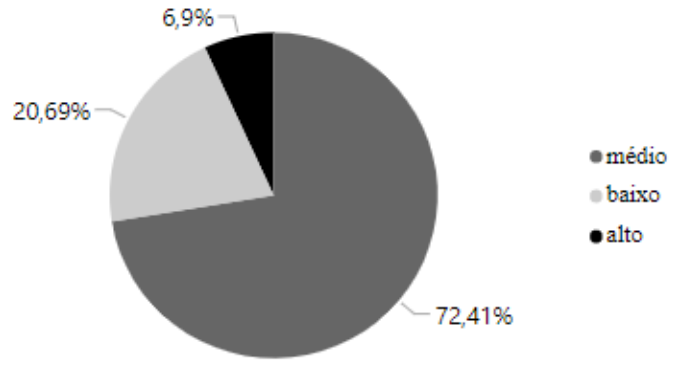

Figura 4. Análise do risco humano e impacto ao abastecimento hídrico.

Fonte: Autor (2021)

\subsection{Resultados agrupados por manifestações patológicas}

A partir da Figura 5 é evidenciado que a corrosão nas vigas de concreto armado é a manifestação patológica mais preponderante, representando 14,08\% das ocorrências, seguida da corrosão na cuba/caixa $(12,85 \%)$ e nos pilares $(12,06 \%)$.

Destaca-se ainda a manifestação patológica mais predominante como sendo a corrosão eletroquímica nos elementos estruturais, o conhecimento desse fator orienta a recuperação e manutenção dessas estruturas de reservação.
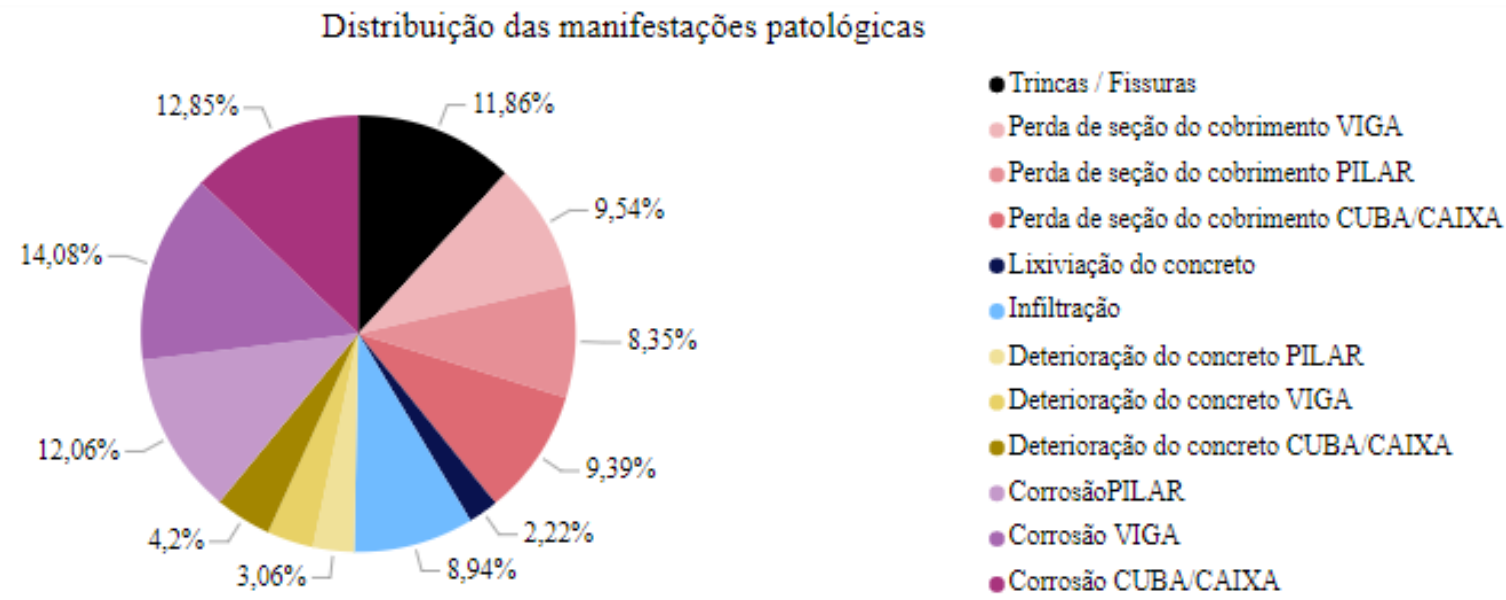

Figura 5. Distribuição de manifestação patológicas por elementos estruturais.

Fonte: Autor (2021)

Para uma classificação do elemento estrutural em relação à sua degradação foi estabelecida uma equação usando parâmetros empíricos, tendo como limites o pior e o melhor elemento estrutural vistoriado, dando fundamentação à Equação 3. Somente considerou manifestações patológicas que afetassem o desempenho estrutural do reservatório como a corrosão eletroquímica, perda de seção de concreto e deterioração do concreto. O resultado da análise dentro do coletado através da Equação 3 é exposto na Tabela 5. 


$$
E e l=a f_{\text {corr }}+a f_{\text {desp }}+a f_{\text {det }}
$$

Onde: Eel $=$ estado do elemento; $a f_{\text {corr }}=$ área afetada por corrosão; $a f_{\text {desp }}=$ área afetada por desplacamento de concreto; $a f_{\text {det }}=$ área afetada por deterioração do concreto.

Tabela 5. Classificação do estado dos elementos estruturais.

\begin{tabular}{|c|c|c|}
\hline Estado & Pontuação & Descrição \\
\hline Bom & $50 \%>$ Eel & $\begin{array}{c}\text { Não possui manifestações patológicas ou } \\
\text { apenas apresenta pequenos indícios de início } \\
\text { do processo. }\end{array}$ \\
\hline Médio & $75 \%>$ Eel $\geq 50 \%$ & $\begin{array}{r}\text { Focos superficiais visíveis da manifestação } \\
\text { patológica, sem danos a estrutura e de fácil } \\
\text { recuperação. }\end{array}$ \\
\hline Ruim & $150 \%>$ Eel $\geq 75 \%$ & $\begin{array}{c}\text { As manifestações patológicas apresentam } \\
\text { riscos estruturais e recuperação custosa, } \\
\text { requerendo maior conhecimento técnico. }\end{array}$ \\
\hline Ruína & Eel $\geq 200 \%$ & $\begin{array}{c}\text { Demanda recuperação urgente. Não } \\
\text { atendendo mais às especificações de projeto } \\
\text { devido à sua degradação estrutural. }\end{array}$ \\
\hline Náno & $\begin{array}{c}\text { Não atende mais às especificações de projeto } \\
\text { e oferece riscos de ruína necessitando } \\
\text { demolição e reconstrução ou encamisamento. }\end{array}$ \\
\hline
\end{tabular}

Fonte: Autor (2021)

\subsubsection{Dos pilares}

A maior parte dos pilares apresentaram-se em um estado bom, considerando a classificação da Tabela 5. No entanto $6,12 \%$ dos pilares encontram-se em um estado de ruína, o que representa 3 reservatórios com pilares em estado de ruína, sendo 1 elevado e 2 apoiados (inativos).

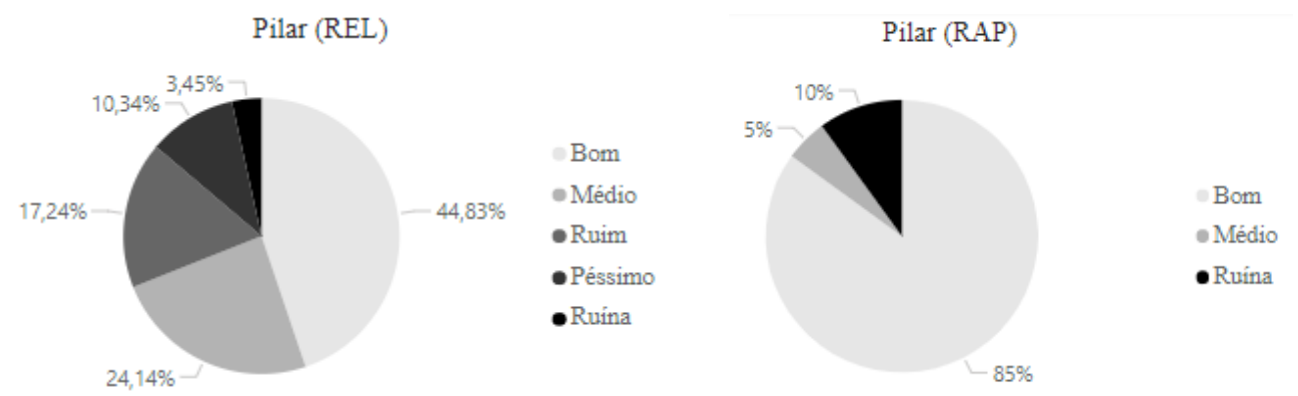

Figura 6. Análise do estado de conservação dos pilares.

Fonte: Autor (2021)

Nos RAP's os pilares permanecem submersos, logo a ausência de oxigênio interrompe a cinética do processo corrosivo. Enquanto os pilares dos REL's estão em contato com uma atmosfera agressiva e, na maioria das vezes, com corrimento e respingo de água clorada em sua superfície, agravando o processo corrosivo no elemento.

Os pilares em estado de ruína nos RAP's foram elementos que, devido à inatividade do reservatório, obtiveram contato com oxigênio e com resistividade baixa devida à penetração de íons cloreto, tendo assim um processo corrosivo intenso. 

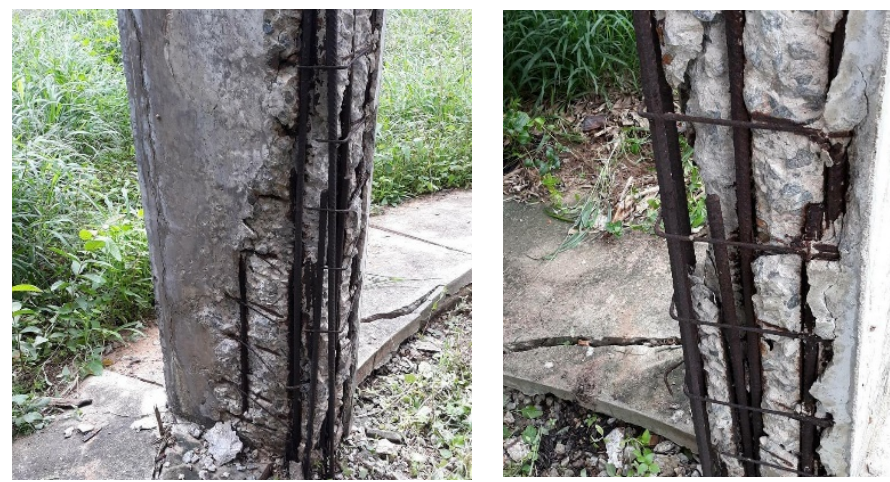

Figura 7. Pilar em estado de ruína em REL.

Fonte: Autor (2021)

\subsubsection{Das vigas}

As vigas encontram-se em sua maior parte com um bom estado, com 37,93\% para os REL's e 45\% para os RAP's. Não obstante, mais de $30 \%$ das vigas apresentam-se em um estado médio e $20 \%$ em um estado ruim, o que permite inferir que as vigas obtiveram um estado de degradação maior que os pilares. Mediante o exposto, as vigas dos REL's demonstraram uma maior degradação em relação a dos RAP's.

Vigas (REL)

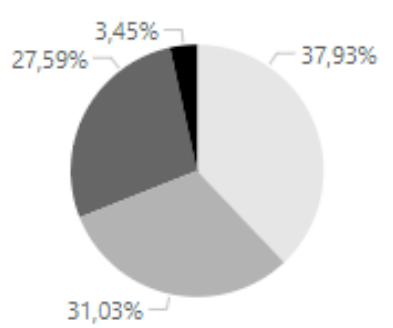

Vigas (RAP)
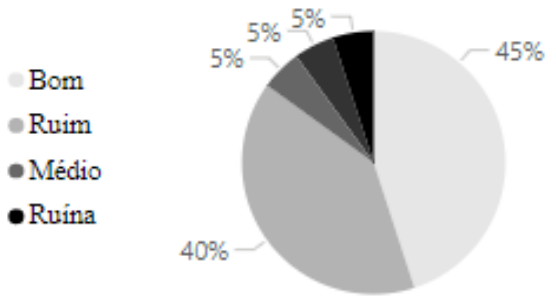

Bom

- Médio

- Péssimo

- Ruim

- Ruina

Figura 8. Análise do estado de conservação das vigas

Fonte: Autor (2021)

As vigas dos RAP's estão submetidas a uma alta agressividade ambiental por estarem em um ambiente confinado com intensa presença de vapores de água clorada. De modo que, por meio da corrosão eletroquímica, tendem a se degradar mais rápido do que as vigas dos REL's, com consequente desplacamento do seu concreto de cobrimento.

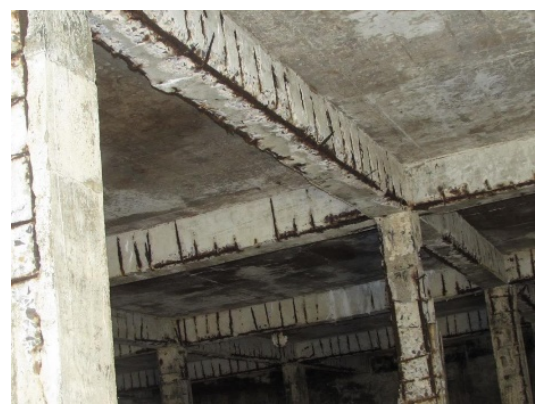

Figura 9. Vigas em estado de ruina em RAP.

Fonte: Autor (2021)

No entanto, como quase todos os REL's possuíam vazamentos nas juntas das tubulações de ferro fundido, as suas respectivas vigas ficavam submetidas à respingos de água clorada constantemente, gerando regiões pontuais de foco de corrosão e desplacamento do concreto. 
Salienta-se também a existência do acúmulo de água nas regiões de engaste viga-pilar da maioria dos REL's. Onde ocorria o processo da corrosão com fissuração do concreto, como consequência tanto da falta de cobrimento, quanto da alta densidade de aço.

\subsubsection{Das caixas/cubas}

As caixas/cubas dos reservatórios são compostas por laje, de topo e de fundo, e paredes de concreto armado. Neste conjunto, o elemento estrutural mais afetado é a região da laje de topo interna à caixa/cuba por não possuir proteção química face os vapores de cloro, resultando em uma intensa corrosão com consequente desplacamento do concreto. Em praticamente todos os reservatórios observou-se a presença desta manifestação.

Apesar de 55,17\% das cubas revelaram-se em um bom estado, apenas $10 \%$ das caixas estavam nesta classificação, conforme exposto na Figura 10. Observou-se ainda que as caixas em sua maioria possuíam grandes focos de corrosão na sua laje de topo interna e uma intensa presença de fissuras e trincas com infiltrações e eflorescências.

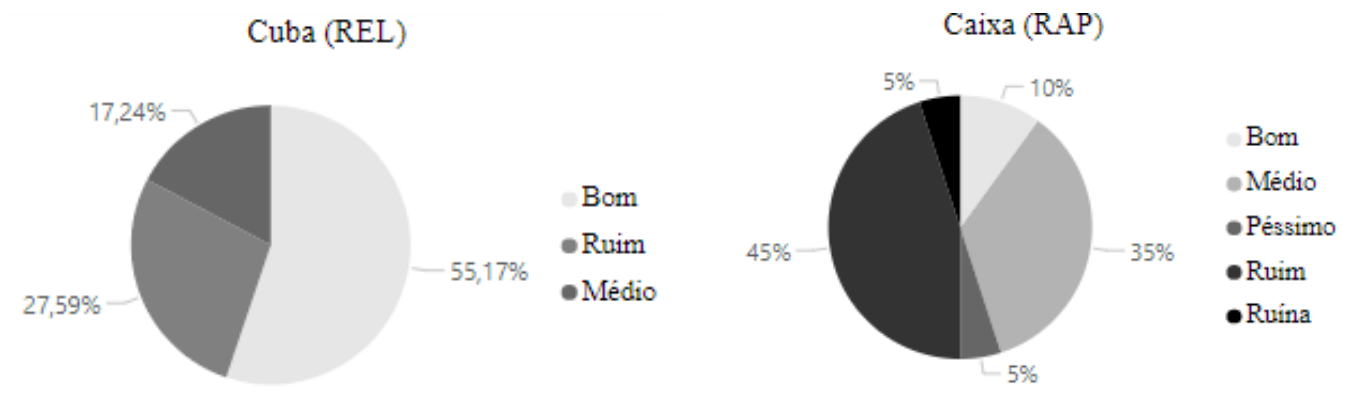

Figura 10. Análise do estado de conservação das caixas/cubas Fonte: Autor (2021)
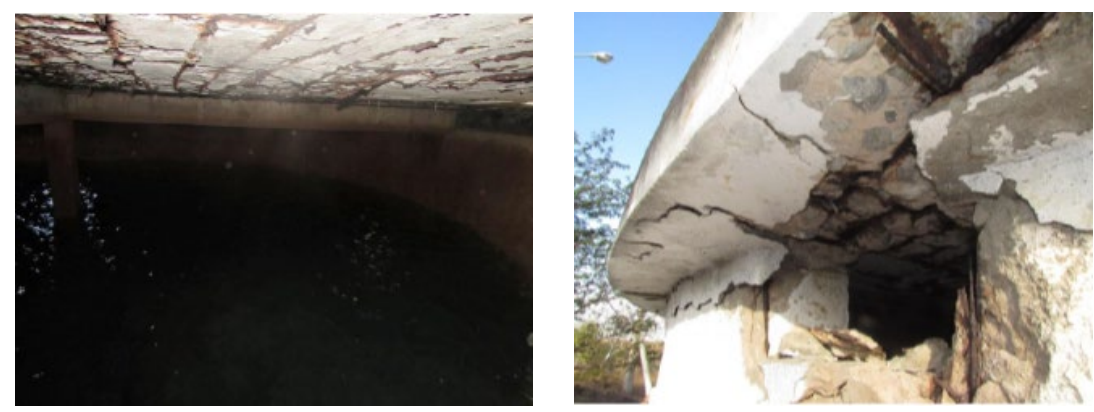

Figura 11. Laje do topo da caixa em estado de ruína Fonte: Autor (2021)
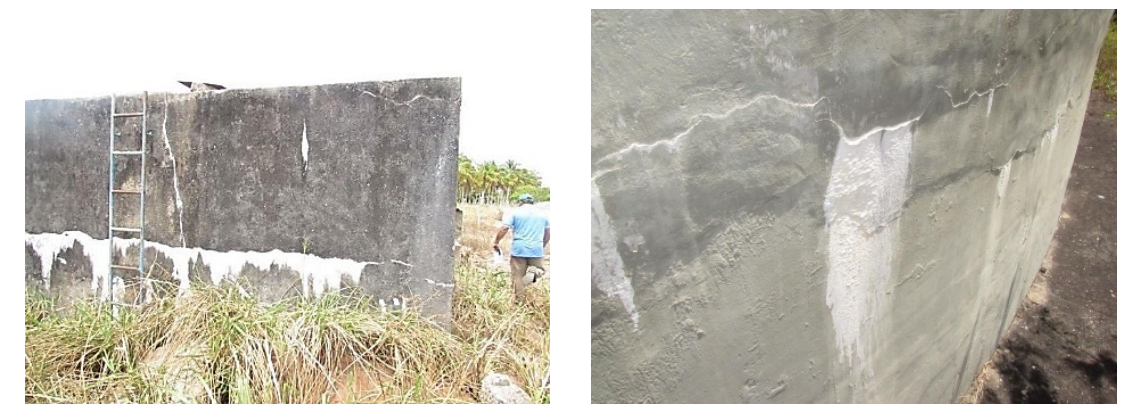

Figura 12. Paredes de caixas em estado ruim 
Fonte: Autor (2021)

\subsubsection{Do estado serviço dos reservatórios}

Cerca de $61 \%$ dos reservatórios possuíam infiltração na sua caixa/cuba, com presença de manchas da parede da estrutura e até mesmo presença de vegetação instalada. Destaca-se que 6 REL's continham vazamentos que inviabilizavam sua operação em sua totalidade de reservação.

Com relação ao desaprumo, apenas 3 REL's encontravam-se nessa situação, destaca-se que um desses se encontrava inativo, Figura 13. Os outros dois reservatórios desaprumados estavam estáveis, sem risco de tombamento e sem manifestação patológica grave em seus pilares, estes podem ser visualizados na Figura 14.

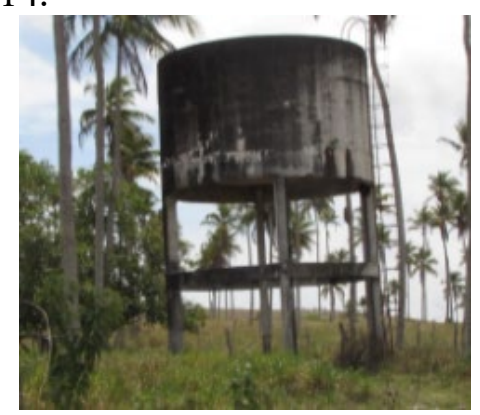

Figura 13. REL desaprumado inativo.

Fonte: Autor (2021)
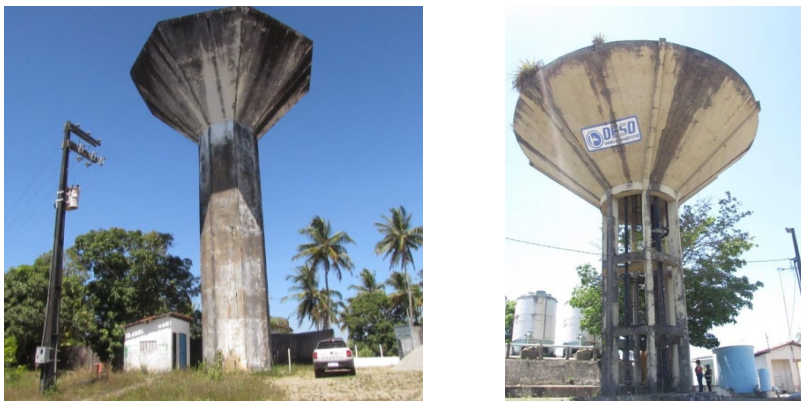

Figura 14. REL's desaprumados ativos.

Fonte: Autor (2021)

\section{CONCLUSÕES}

A realização de inspeções periódicas de nível 1 é fato obrigatório a toda e qualquer estrutura, independentemente de seu sistema construtivo. No entanto, a cultura de inspeção e manutenção preventiva não é prioritária na maior parte das vezes. A realização das vistorias evidenciou o impacto dessa negligência, apontando o mau envelhecimento das estruturas de concreto armado dos reservatórios, que sem a devida manutenção ficaram à deriva do tempo.

Com a utilização da metodologia desenvolvida neste trabalho foi possível a realização de uma lista de priorização, para realização de inspeção a nível 2, com elaboração de projetos de recuperação em reforço condizentes com a realidade, isto é, o critério empírico do modelo permitiu uma adequação dos casos para com as suas respectivas análises.

A partir da análise quanti-qualitativa, pôde-se avaliar as manifestações patológicas mais presentes e constantes nas estruturas, no caso apresentado, a corrosão eletroquímica. O conhecimento deste fator é importante para a elaboração de planos de manutenção. 


\section{REFERÊNCIAS}

ASSOCIAÇÃO BRASILEIRA DE NORMAS TÉCNICAS (ABNT). NBR 15.575-2: Edificações Habitacionais - Desempenho - Parte 2: Requisitos para os Sistemas Estruturais. Rio de Janeiro: ABNT, 2013.

ASSOCIAÇÃO BRASILEIRA DE NORMAS TÉCNICAS (ABNT). NBR 16747: Inspeção predial - Diretrizes, conceitos, terminologia e procedimento. Rio de janeiro: ABNT,2020.

Caixa d'água desaba e mata duas crianças em escola de Nossa Senhora das Dores, diz polícia. G1, Sergipe, 06 de nov. de 2017. Disponível em: <http://www.f5news.com.br/cotidiano/corrosaoprecoce-de-estrutura-levou-a-queda-da-caixa-d\%EF\%BF\%BDagua-em-dores-se_42975/>.

Acessado em 22 de jul. 2021.

GOMIDE, T. L. F.; PUJADAS, F. Z. A.; FAGUNDES NETO, J. C. P. Engenharia diagnóstica em edificações. São Paulo: Pini, 2009.

INSTITUTO BRASILEIRO DE AVALIAÇÃO E PERÍCIAS (IBAPE). Norma de Inspeção Predial Nacional. São Paulo, 2012. 18p.

INSTITUTO BRASILEIRO DE AVALIAÇÃO E PERÍCIAS DE SÃO PAULO (IBAPE). Norma de Inspeção Predial. São Paulo, 2007. 32p.

Laudo do Crea-SE aponta que corrosão provocada pela falta de manutenção causou queda de peça metálica no Shopping Jardins. CREA, Sergipe, 26 de jul. de 2016. Disponível em: $<$ http://www.crea-se.org.br/laudo-do-crea-se-aponta-que-corrosao-provocada-pela-falta-demanutencao-causou-queda-de-peca-metalica-no-shopping-jardins/>. Acesso em: 22 de jul. de 2021.

LUCINDA, M. A. Qualidade: fundamentos e práticas para cursos de graduação. Rio de Janeiro: Brasport, 2010.

Ponte desaba e rompe tubulação de água em Pedra Branca, SE. G1, Sergipe, 09 de mai. de 2015. Disponível em: <http://g1.globo.com/se/sergipe/noticia/2015/05/ponte-desaba-e-rompetubulacao-de-agua-em-pedra-branca-se.html>. Acesso em: 22 de jul. de 2021.

SHAH, S.P.; SWARTZ, S.E.; OUYANG, C. Fracture mechanics of concrete -applications of fracture mechanics to concrete, rock and other quasi-brittle materials, New York, John Wiley \& Sons, 1995. 